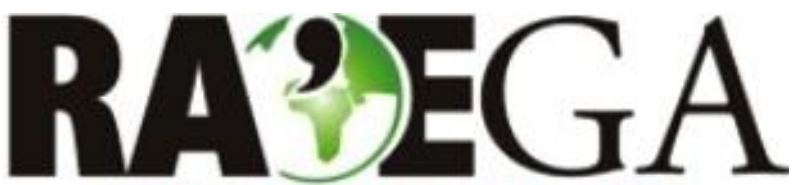

O ESPAÇO GEOGRÁFICO EM ANÁLISE

\title{
CONDICIONANTES GEOGRÁFICOS DA TEMPERATURA DO AR NO ESTADO DO PARANÁ
} GEOGRAPHIC CONTROLLING FACTORS OF THE AIR TEMPERATURE IN THE STATE OF PARANÁ

\author{
Otavio Cristiano Montanher ${ }^{1}$, Cíntia Minaki ${ }^{2}$
}

\section{RESUMO}

Variáveis geográficas são comumente utilizadas para modelagem da temperatura do ar. Com o objetivo de compreender os fatores de controle desse elemento climático no Estado do Paraná, se buscou avaliar a contribuição de quatro variáveis: latitude, longitude, altitude e oceanidade. Para isso, foram obtidas séries históricas de temperatura média, mínima e máxima em 37 estações meteorológicas. Os dados passaram por um processo de reconstituição, resultando em séries mensais contínuas para o período entre out./1976 a dez./2015. Com uso de regressão linear múltipla, se modelou 39 variáveis: três valores anuais e 36 mensais. Em geral, os modelos apresentaram resultados satisfatórios, principalmente para a temperatura média $\left(0,88<R^{2}<0,97\right)$ e máxima $\left(0,92<R^{2}<0,94\right)$, enquanto os modelos para estimativa da temperatura mínima tiveram resultados um pouco inferiores $\left(0,72<R^{2}<0,93\right)$. Pela análise dos coeficientes dos modelos, se concluiu que: i) a altitude e a latitude possuem relações inversamente proporcionais com a temperatura do ar, enquanto a longitude possui relação proporcional; ii) a variável região, aplicada para simular o forte efeito de oceanidade que ocorre sobre o litoral do Estado, demonstrou uma dinâmica mais complexa do que as outras variáveis, com influência oposta no verão e no inverno, e pouca implicação nas estações de transição; iii) a importância das variáveis para os modelos não é a mesma para as três estatísticas descritivas e não é constante ao longo do ano. Adicionalmente, os modelos permitem a espacialização da temperatura do ar para o Estado do Paraná.

Palavras chave: Oceanidade; Regressão múltipla; Altitude; Latitude; Longitude.

\section{ABSTRACT}

Geographical variables are commonly used for modelling of air temperature. The aim of this paper was to understand the following controlling factors of the air temperature in the State of Paraná, Brazil: latitude, longitude, altitude and oceanicity. Were obtained historical series of average, minimum and maximum temperatures from 37 meteorological stations. These series were submitted to a reconstitution process, resulting in continual monthly series for the period from oct./1976 to dec./2015. By using multiple linear regression, were modeled 39 variables: three annual and 36 monthly values. By and large, the models showed suitable results, mainly for the average $(0,88$ $\left.<\mathrm{R}^{2}<0,97\right)$ and maximum values $\left(0,92<\mathrm{R}^{2}<0,94\right)$, whilst the models for estimating the minimum values were slightly inferior $\left(0,72<R^{2}<0,93\right)$. Based on the analysis of the model's coefficients, the following conclusions were obtained: i) altitude and latitude have inversely proportional relationships with the air temperature, whilst longitude has a proportional one; ii) the variable called as region, made to simulate the strong oceanicity effect that occurs on the State's littoral, has more complex behavior than the other three variables. That variable worked to minimize the extreme temperatures in the littoral region, as expected for a region under oceanic influence; iii) the variables importance for the models is not equal for the three descriptive statistics and it is not constant throughout the year. Additionally, the models permit the air temperature spatialization for the State of Paraná.

Keywords: Oceanicity; Multiple regression; Altitude; Latitude; Longitude.

\footnotetext{
${ }^{1}$ Universidade Estadual de Maringá,Maringá/PR, email: otaviocmontanher@yahoo.com.br

2 Universidade Estadual de Maringá,Maringá/PR, email: cminaki@uem.br
} 


\section{CONDICIONANTES GEOGRÁFICOS DA TEMPERATURA NO AR NO ESTADO DO PARANÁ}

\section{INTRODUÇÃO}

A temperatura é elemento climático associado às mensurações feitas no ar, na água e no solo, constituindo diferentes modalidades para os propósitos da análise sinótica e climatológica. A temperatura do ar, especificamente aquela medida à superfície, em valores médios, máximos e mínimos, é parâmetro importante para os estudos geográficos. Sua dinâmica é influenciada por variações espaciais e temporais, que determinam a formação de ambientes termicamente homogêneos ou contrastantes.

A natureza oceânica ou continental é exemplo de variação espacial que explica a amplitude térmica nos dois tipos de superfície, que se distinguem, entre outros aspectos, pelo calor específico. "O aquecimento diferenciado das águas oceânicas e das superfícies dos continentes, mais lento nas primeiras devido à sua maior capacidade de reter calor, favorece a redução das amplitudes térmicas diárias das áreas sob influência da circulação marítima" (MENDONÇA; DANNI-OLIVEIRA, 2007, p. 49). Localidades distantes da costa, mesmo que se situem à mesma latitude, podem ostentar gradientes térmicos bem maiores que das áreas litorâneas, e a este efeito se denomina continentalidade. Em algumas circunstâncias, a expressão da continentalidade pode ser substituída pela latitude ou pela longitude, conforme a posição relativa do mar e a análise da direção do vento predominante (VAREJÃO-SILVA, 2006, p. 78).

Além da influência das áreas adjacentes (oceanidade e continentalidade), outros atributos de cada superfície podem prevalecer, como a latitude e a altitude. É na faixa latitudinal entre $17,5^{\circ}$ e $23,5^{\circ}$ que os raios solares chegam verticalmente, quase a pino, por aproximadamente três meses consecutivos durante o solstício de verão de ambos os hemisférios, permitindo grande acúmulo de calor e temperaturas elevadas na superfície. Logo, as zonas de aquecimento máximo ocorrem mais próximas dos trópicos do que do equador (BARRY; CHORLEY, 2013, p. 50), e a distribuição espacial da temperatura do ar assume padrões distintos nos meses representativos, sobretudo do verão e do inverno (MENDONÇA; DANNIOLIVEIRA, 2007, p. 55). Quanto à altitude e aos efeitos topográficos, a troposfera possui um gradiente de redução vertical da temperatura de $6,5^{\circ} \mathrm{C} / \mathrm{km}$, que não se mantém constante, seja pela variação da altura, como pela sazonalidade ou localização da área (BARRY; CHORLEY, 2013, p. 62).

Em âmbito nacional, muitos autores utilizaram variáveis geográficas como condicionantes da temperatura do ar para modelagem em áreas e intervalos temporais distintos. Em escala mensal, Valeriano e Picini (2003), para o Estado de São Paulo com finalidade agroclimatológica. Em escala decendial, Cargnelutti Filho et al. (2006), que estimaram a temperatura média mínima para o Rio Grande do Sul, área também enfocada por Cargnelutti Filho, Maluf e Matzenauer (2008), que calcularam a temperatura média e a média máxima pelas mesmas variáveis independentes altitude, latitude e longitude.

O elemento climático temperatura do ar em suas variações de valores (média, máxima e mínima) foi estimado em diversos modelos de regressão múltipla abrangendo, sobretudo, estados e regiões (OLIVEIRA NETO et al., 2000), para fins de zoneamento agroclimatológico (BARBARISI et al., 2006; BARDIN; PEDRO JÚNIOR; MORAES, 2010). Nesta perspectiva, também foram delimitados os riscos climáticos para culturas no Estado do Paraná, na iminência, principalmente de geadas (RICCE et al., 2014a; RICCE et al., 2014b). Paula (2005), ao avaliar a relação entre os elementos climáticos de temperatura do ar e precipitação e a incidência de dengue no Estado do Paraná, utilizou a regressão múltipla para espacialização da temperatura, considerando a altitude, a latitude e a distância do oceano.

Com base nas referências mencionadas, se notou que muitos trabalhos que utilizam a análise de regressão para modelagem da temperatura do ar são desenvolvidos principalmente no âmbito das ciências agrárias, 


\section{CONDICIONANTES GEOGRÁFICOS DA TEMPERATURA NO AR NO ESTADO DO PARANÁ}

no contexto nacional. Comumente, objetivam o zoneamento agroclimático de culturas específicas. Em direção oposta, este trabalho não busca a geração de produtos para aplicação em culturas agrícolas e sim a própria compreensão dos condicionantes geográficos que determinam a temperatura do ar no Estado do Paraná. Esta ainda é uma abordagem pouco difundida na prática geográfica brasileira.

Especificamente, este trabalho possui as seguintes questões, todas voltadas à área de estudo já mencionada: qual é a distribuição espacial da temperatura do ar? Como é sua variação de acordo com a altitude, latitude, longitude e a oceanidade? Tais fatores manifestam a mesma importância para as temperaturas mínimas, médias e máximas? Tais fatores incidem com a mesma importância no decorrer do ano?

\section{MATERIAIS E MÉTODOS}

A metodologia consistiu primeiramente na seleção das estações meteorológicas e reconstituição de suas séries históricas (Figura 1). Após essa organização, se aplicou dois conjuntos de regressões, um a partir dos dados originais e outro a partir dos dados padronizados. Os modelos convencionais foram utilizados para espacialização da temperatura do ar e os modelos padronizados para análise da contribuição de cada variável. No contexto da análise das variáveis, foi feito o cálculo da irradiância solar para o decorrer de um ano completo, em diferentes faixas de latitude.

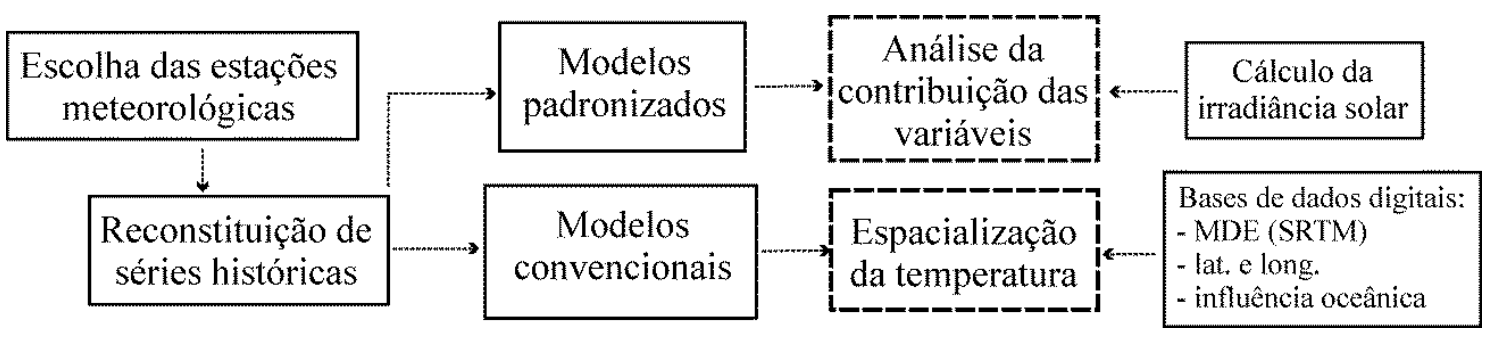

Figura 1 - Fluxograma metodológico.

\subsection{BASE DE DADOS}

Fez-se uma busca por dados de temperatura do ar a partir de duas fontes, o Instituto Nacional de Meteorologia (INMET) e o Instituto Agronômico do Paraná (IAPAR). O INMET possui séries históricas de dados de temperatura do ar em oito estações meteorológicas ao longo do Estado (Figura 2), as quais foram acessadas livremente por meio do Banco de Dados Meteorológicos (BRASIL, 2017). O IAPAR abrange uma rede com diversas estações meteorológicas no Estado do Paraná (IAPAR, 2017). Dessa fonte, foram obtidos dados diários de 36 estações meteorológicas (Figura 2).

Considerando as duas fontes, houve disponibilidade de 44 estações, mas nem todas tiveram seu banco de dados selecionado. Algumas estações meteorológicas estão situadas no mesmo município em ambas as bases de dados. Nesses casos se optou pela série histórica com menos falhas, considerando que essa abrangesse o período de análise, enquanto em outros casos as séries eram demasiadamente curtas. A distribuição geográfica de todas as estações meteorológicas pode ser observada na Figura 2, incluindo as que foram descartadas da análise.

As séries históricas de ambas as fontes possuem uma grande variação dos períodos de abrangência. Muitas estações meteorológicas do IAPAR iniciaram o registro de dados em jan./1976, e algumas continuam em operação até a atualidade. Portanto, optou-se pelo período de out./1976 a dez./2015, que totaliza pouco mais de 39 anos completos.

Como o objetivo desta pesquisa foi avaliar a importância dos condicionantes geográficos para a temperatura do ar (mínima, média e máxima), e não a ocorrência de eventos específicos, optou-se por utilizar a periodicidade 


\section{CONDICIONANTES GEOGRÁFICOS DA TEMPERATURA NO AR NO ESTADO DO PARANÁ}

mensal. Os dados do INMET foram adquiridos nesta escala temporal, enquanto os dados do IAPAR são diários. Portanto, esses dados necessitaram de uma transformação para séries mensais, o que foi feito em ambiente $R$ ( $R$ CORE TEAM, 2017), especificamente com o pacote hydroTSM (ZAMBRANO-BIGIARINI, 2014).
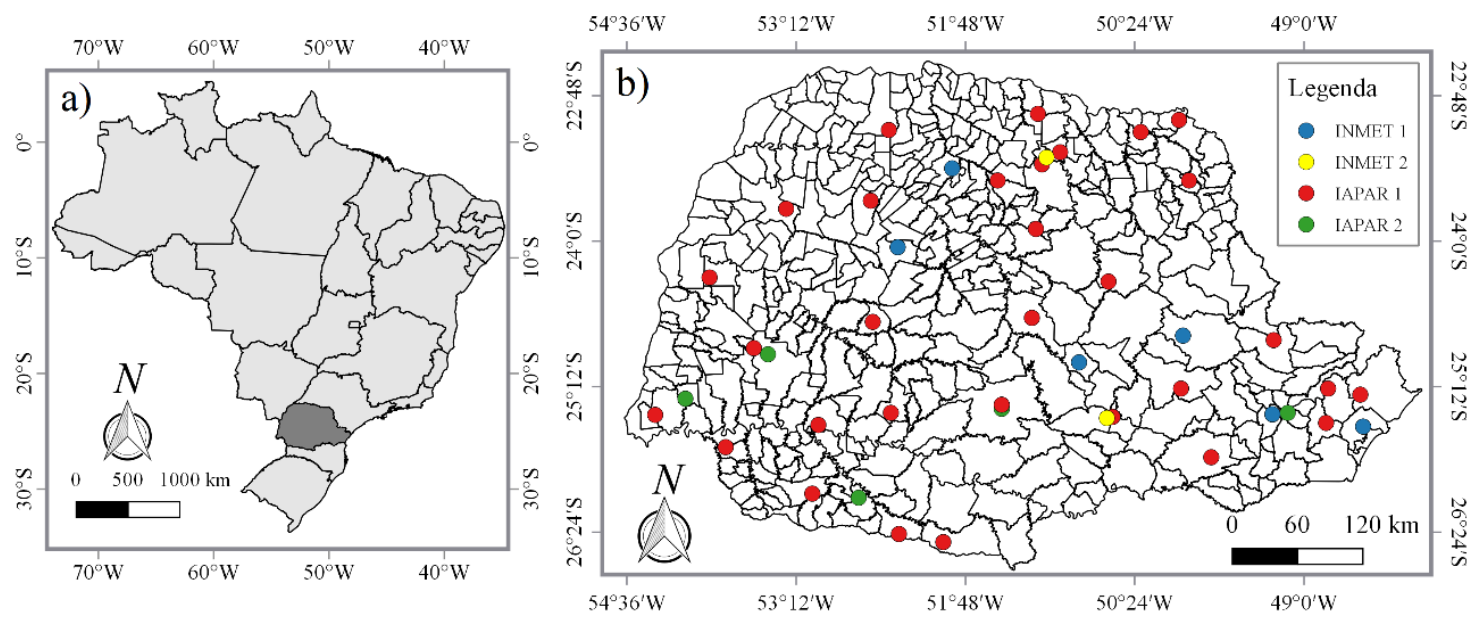

Figura 2 - Brasil, com destaque para o Estado do Paraná (a). Limites municipais do Estado e localização de todas as estações meteorológicas consultadas (b). INMET 1 e IAPAR 1 representam as estações utilizadas (azul e vermelho), enquanto INMET 2 e IAPAR 2 (amarelo e verde) correspondem às estações que foram descartadas. Sistema de referência de coordenadas: EPSG 4326 (datum WGS 84 e projeção lat/long).

\subsection{Reconstituição das séries históricas}

A avaliação exploratória das séries históricas originais mostrou que boa parte possuía falhas (períodos sem obtenção de dados de até poucos meses), e mesmo longos períodos sem aquisição de dados (mais do que uma década, em alguns casos). Foram feitas estimativas para os dois casos, e para fins de simplificação terminológica, foi utilizado o termo "reconstituição de série histórica".

Para a reconstituição das séries se adotou a análise de regressão múltipla, uma das mais utilizadas entre todos os métodos estatísticos (KUTNER et al., 2005). A análise de regressão é apontada em alguns estudos de casos, como uma boa opção para preenchimento de falhas em dados meteorológicos no Brasil (VENTURA et al., 2016; MELLO et al., 2017).

Durante a análise de regressão, entendeu-se que um mês faltante de uma série obtida em uma determinada estação é a variável a ser estimada, que, no caso da regressão, será entendida como variável dependente, ou simplesmente " $Y$ ". Os valores de temperatura do ar (mínima, média e máxima) foram estimados a partir dos valores registrados nas estações meteorológicas que possuem maior relação com a estação em reconstituição, dentre as que estão mais próximas e que possuem dados registrados no período de interesse. Cada estação utilizada para realização dessa estimativa é uma variável independente no modelo de regressão, ou simplesmente " $X$ ".

A reconstituição de séries históricas envolveu o uso de modelos de primeira ordem com duas ou mais variáveis de interesse (KUTNER et al., 2005):

$$
Y_{\mathrm{i}}=\beta_{0}+\beta_{1} X_{\mathrm{i} 1}+\beta_{2} X_{\mathrm{i} 2}+\cdots \beta_{\mathrm{p}-1} X_{\mathrm{i}, \mathrm{p}-1}+\varepsilon_{\mathrm{i}}
$$

Em que:

$Y=$ variável dependente;

$\mathrm{X}_{1 \ldots \mathrm{p}-1}=$ variável independente;

$\mathrm{p}=$ número de parâmetros;

$B_{0}=$ intercepto;

$B_{1 \ldots p-1}=$ coeficiente angular;

$\varepsilon=$ erro. 


\section{CONDICIONANTES GEOGRÁFICOS DA TEMPERATURA NO AR NO ESTADO DO PARANÁ}

A análise de regressão foi executada em ambiente R, por meio da função "Im" (linear model), incluída em sua versão básica (R CORE TEAM, 2017).

\subsection{Obtenção de modelos via regressão linear múltipla}

Após a reconstituição das séries históricas, um novo conjunto de análises de regressão foi executado. Nesse momento, a variável dependente foi a temperatura (em suas três métricas), enquanto houve quatro variáveis independentes: altitude, latitude, longitude e região. Essa análise teve como objetivo a obtenção de modelos para estimativa da temperatura do ar, apenas a partir das características geográficas de cada ponto específico do Estado. Esse segundo momento de modelagem envolveu as métricas mínimas, médias e máximas anuais (3 valores) e as mensais (36 valores), resultando em 39 análises de regressão.

Os dados de latitude, longitude e altitude de todas as estações meteorológicas encontram-se na Tabela 1. A definição numérica dessas variáveis é simples, enquanto que a oceanidade é um efeito mais complexo de ser mensurado. A definição de uma variável com esse intuito foi atingida somente durante a avaliação exploratória das relações entre cada uma das variáveis e a temperatura do ar. Notouse o padrão de que a temperatura registrada em quatro estações meteorológicas é mais baixa do que o esperado para suas respectivas altitudes, conforme uma reta ajustada para o conjunto restante de dados (Figura 3).

Embora a diferença seja maior para as temperaturas extremas, a análise da relação representada na Figura 3 mostra que as mesmas quatro estações possuem temperaturas (mínimas, médias e máximas) inferiores ao que seria esperado para suas faixas de altitude. As quatro estações são: Paranaguá, Antonina, Morretes e Guaraqueçaba (Tabela 1). Ao se verificar sua localização, notou-se que se situam em uma região específica do Estado, próxima ao oceano (Figura 4). Essas estações são as mesmas utilizadas por Vanhoni e Mendonça (2008), para caracterização da temperatura do ar no litoral do Estado do Paraná.

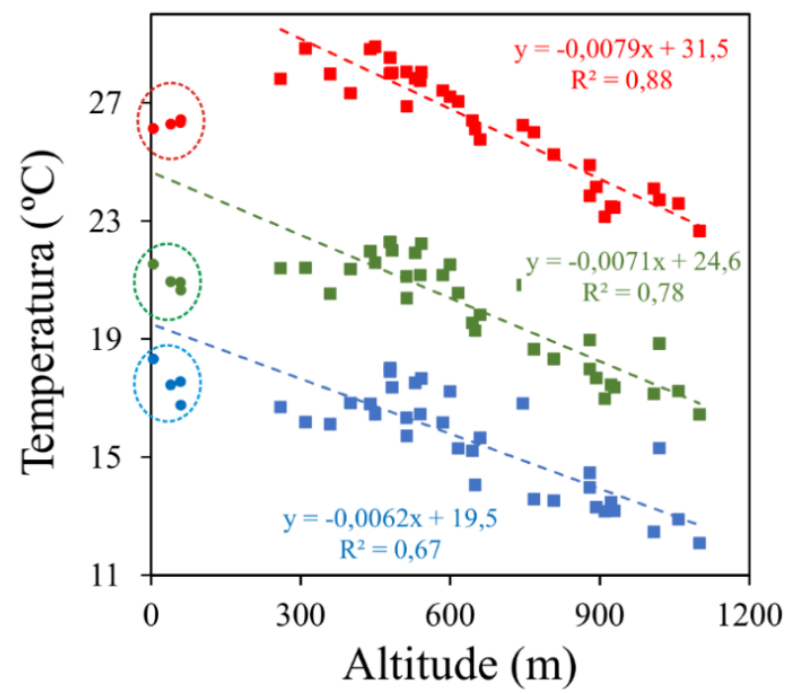

Figura 3 - Relação entre temperatura do ar anual média e altitude. São apresentados três conjuntos: temperatura mínima (azul), média (verde) e máxima (vermelho). Observar os conjuntos circulados. 
MONTANHER, O. C., MINAKI, C.

\section{CONDICIONANTES GEOGRÁFICOS DA TEMPERATURA NO AR NO ESTADO DO PARANÁ}

Tabela 1 - Descrição das estações meteorológicas utilizadas na pesquisa.

\begin{tabular}{|c|c|c|c|c|c|c|}
\hline Estação & Fonte & Código & Altitude (m) & Latitude ( $\left.{ }^{\circ} \mathrm{S}\right)$ & Longitude $\left({ }^{\circ} \mathrm{W}\right)$ & Região \\
\hline Campo Mourão & INMET & 83783 & 616,4 & $-24,05$ & $-52,36$ & Interior \\
\hline Castro & INMET & 83813 & 1008,8 & $-24,78$ & -50 & Interior \\
\hline Curitiba & INMET & 83842 & 923,5 & $-25,43$ & $-49,26$ & Interior \\
\hline Ivaí & INMET & 83811 & 808 & -25 & $-50,86$ & Interior \\
\hline Maringá & INMET & 83767 & 542 & $-23,4$ & $-51,91$ & Interior \\
\hline Paranaguá & INMET & 83844 & 4,5 & $-25,53$ & $-48,51$ & Litoral \\
\hline Bela V. Paraíso & IAPAR & 2251027 & 600 & $-22,95$ & $-51,2$ & Interior \\
\hline Joaquim Távora & IAPAR & 2349030 & 512 & $-23,5$ & $-49,95$ & Interior \\
\hline Cambará & IAPAR & 2350017 & 450 & -23 & $-50,03$ & Interior \\
\hline Bandeirantes & IAPAR & 2350018 & 440 & $-23,1$ & $-50,35$ & Interior \\
\hline Londrina & IAPAR & 2351003 & 585 & $-23,36$ & $-51,16$ & Interior \\
\hline Apucarana & IAPAR & 2351008 & 746 & $-23,5$ & $-51,53$ & Interior \\
\hline Ibiporã & IAPAR & 2351011 & 484 & $-23,26$ & $-51,01$ & Interior \\
\hline Mauá da Serra & IAPAR & 2351063 & 1020 & $-23,9$ & $-51,21$ & Interior \\
\hline Paranavaí & IAPAR & 2352017 & 480 & $-23,08$ & $-52,43$ & Interior \\
\hline Cianorte & IAPAR & 2352019 & 530 & $-23,66$ & $-52,58$ & Interior \\
\hline Umuarama & IAPAR & 2353008 & 480 & $-23,73$ & $-53,28$ & Interior \\
\hline Cerro Azul & IAPAR & 2449013 & 360 & $-24,81$ & $-49,25$ & Interior \\
\hline Telêmaco Borba & IAPAR & 2450011 & 768 & $-24,33$ & $-50,61$ & Interior \\
\hline Candido de Abreu & IAPAR & 2451052 & 645 & $-24,63$ & $-51,25$ & Interior \\
\hline Nova Cantú & IAPAR & 2452050 & 540 & $-24,66$ & $-52,56$ & Interior \\
\hline Palotina & IAPAR & 2453003 & 310 & $-24,3$ & $-53,91$ & Interior \\
\hline Cascavel & IAPAR & 2453023 & 660 & $-24,88$ & $-53,55$ & Interior \\
\hline Morretes & IAPAR & 2548038 & 59 & $-25,5$ & $-48,81$ & Litoral \\
\hline Guaraqueçaba & IAPAR & 2548039 & 40 & $-25,26$ & $-48,53$ & Litoral \\
\hline Antonina & IAPAR & 2548070 & 60 & $-25,21$ & $-48,8$ & Litoral \\
\hline Lapa & IAPAR & 2549091 & 910 & $-25,78$ & $-49,76$ & Interior \\
\hline Ponta Grossa & IAPAR & 2550024 & 880 & $-25,21$ & $-50,01$ & Interior \\
\hline Fernandes Pinheiro & IAPAR & 2550025 & 893 & $-25,45$ & $-50,58$ & Interior \\
\hline Guarapuava & IAPAR & 2551010 & 1058 & $-25,35$ & $-51,5$ & Interior \\
\hline Laranjeiras do Sul & IAPAR & 2552009 & 880 & $-25,41$ & $-52,41$ & Interior \\
\hline Planalto & IAPAR & 2553015 & 400 & $-25,7$ & $-53,78$ & Interior \\
\hline Quedas do Iguaçu & IAPAR & 2553018 & 513 & $-25,51$ & $-53,01$ & Interior \\
\hline São Miguel Iguaçu & IAPAR & 2554026 & 260 & $-25,43$ & $-54,36$ & Interior \\
\hline Palmas & IAPAR & 2651043 & 1100 & $-26,48$ & $-51,98$ & Interior \\
\hline Clevelândia & IAPAR & 2652003 & 930 & $-26,41$ & $-52,35$ & Interior \\
\hline Francisco Beltrão & IAPAR & 2653012 & 650 & $-26,08$ & $-53,06$ & Interior \\
\hline
\end{tabular}




\section{CONDICIONANTES GEOGRÁFICOS DA TEMPERATURA NO AR NO ESTADO DO PARANÁ}

Esse fato fez com que fosse proposta a variável independente região como um proxy para o efeito de oceanidade (Tabela 1). A terminologia utilizada neste estudo segue a de Valeriano e Picini (2000, 2003), ao analisarem a temperatura do ar no Estado de São Paulo. Tais autores, no entanto, realizaram duas análises de regressão distintas conforme essas duas situações geográficas, ao passo que neste estudo a região foi modelada como uma variável categórica. Em regressão, a variável região passa a ser entendida como uma variável binária: 0, 1 (KUTNER et al., 2005).

A hipótese associada a esta proposição está ligada às influências que o oceano pode ter sobre a temperatura do ar em suas áreas imediatamente adjacentes, bem como a forte influência orográfica que a Serra do Mar possui no Estado do Paraná. Neste sentido, Vanhoni e Mendonça (2008) observaram importantes relações causais entre a temperatura do ar, a influência oceânica e a altitude no litoral do
Estado, as quais provavelmente não devem ser as mesmas no interior.

A seleção de variáveis para cada regressão, dentre as quatro pré-definidas, ocorreu por meio do método Stepwise (KUTNER et al., 2005). Adotou-se a eliminação backward, conforme o AIC (Akaike information criteria KUTNER et al., 2005).

\subsection{Espacialização da temperatura}

Após a obtenção dos modelos, a temperatura do ar para cada mês foi espacializada a partir de bases de dados matriciais das coordenadas geográficas (latitude e longitude), do efeito de oceanidade e da altitude obtida por meio do MDE SRTM (Figura 5). As bases de latitude, longitude e oceanidade possuem a mesma resolução do MDE de entrada, de 3 arcos de segundo (USGS, 2017). Todas as operações espaciais, bem como a elaboração dos mapas foi feita com uso do software QGIS (QGIS DEVELOPMENT TEAM, 2009).
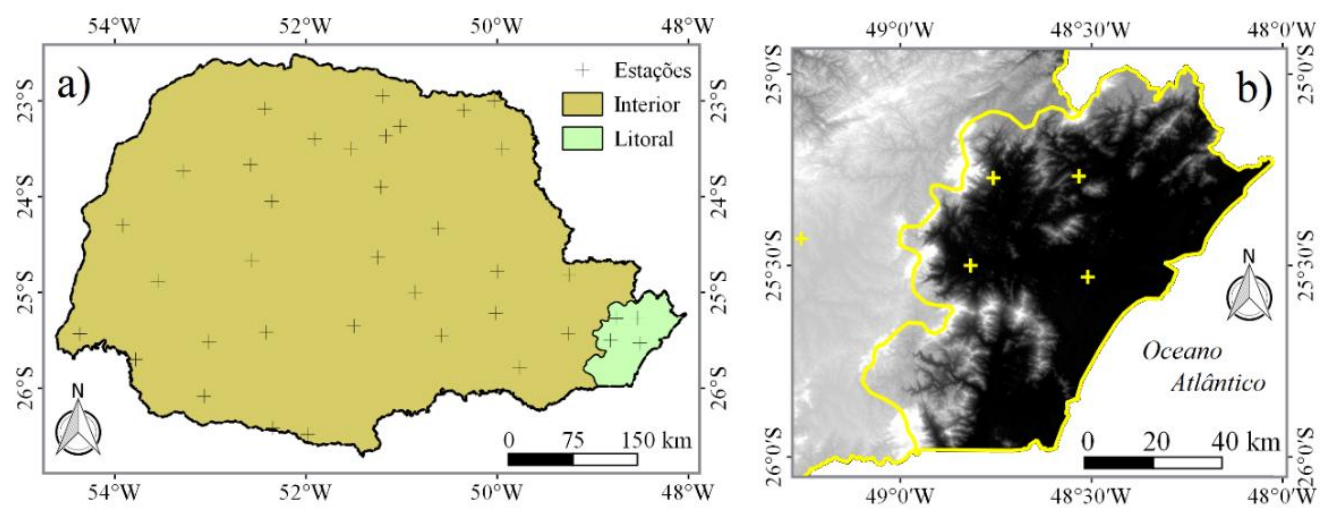

Figura 4 - Divisão proposta para o Estado do Paraná em duas regiões: interior e litoral (a).

Representação do MDE SRTM em tons de cinza para a região do litoral, contendo os limites propostos e as estações meteorológicas mencionadas no texto (b). Sistema de referência de coordenadas: EPSG 4326 (datum WGS 84 e projeção lat/long). 


\section{CONDICIONANTES GEOGRÁFICOS DA TEMPERATURA NO AR NO ESTADO DO PARANÁ}
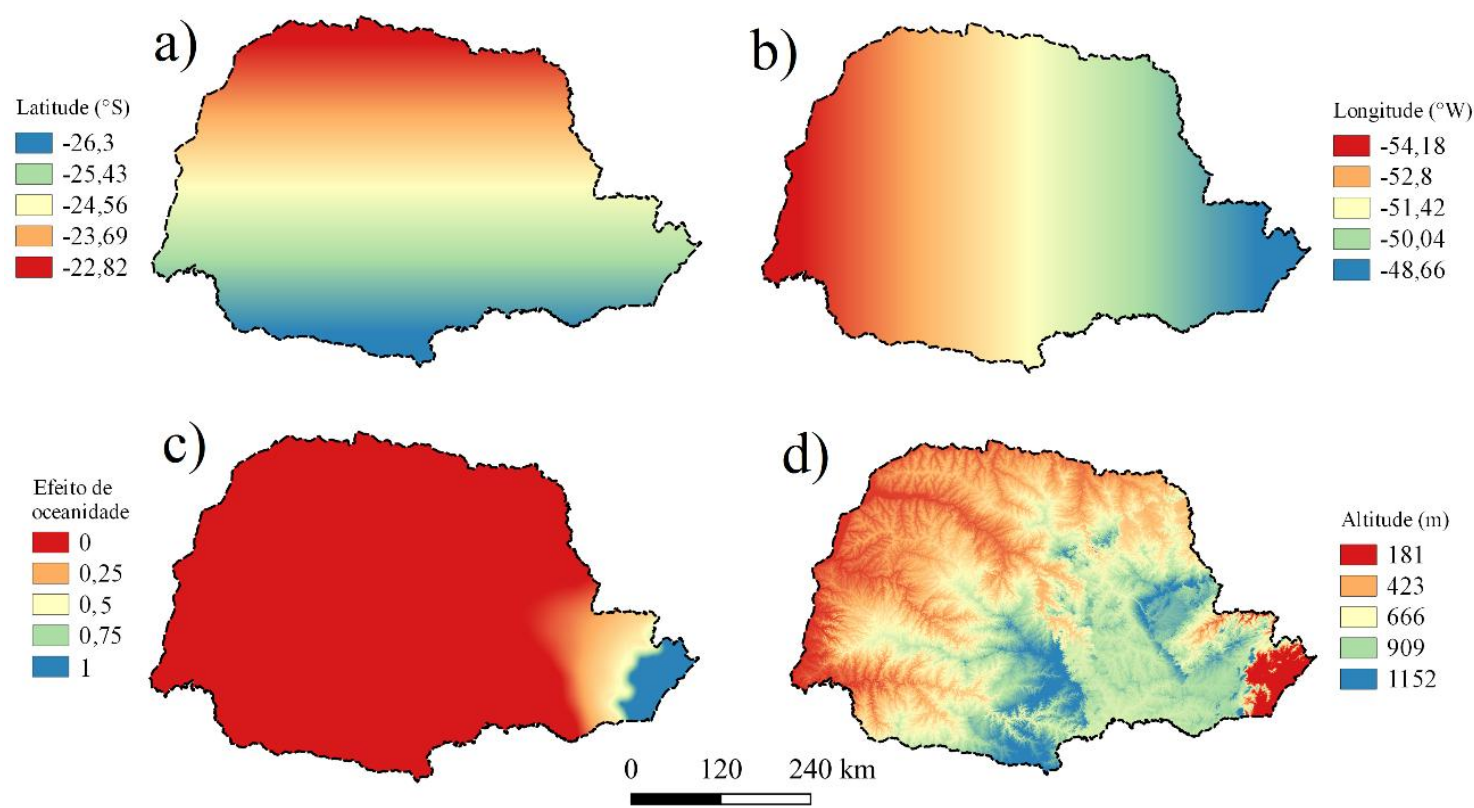

Figura 5 - Bases matriciais de: latitude (a); longitude (b); oceanidade (c) e altitude (d).

O uso da região como uma variável categórica na análise de regressão resulta em valores de coeficientes que serão adicionados ou subtraídos à soma total da equação linear. Isso implica na geração de feições com forte contraste na divisa entre as duas regiões definidas, problema semelhante ao encontrado por Valeriano e Picini (2003) no Estado de São Paulo. O tratamento destas feições indesejáveis foi feito a partir da definição de uma camada de pesos entre 0 e 1 (Figuras 5 e 6). A região do litoral, com efeito pronunciado de oceanidade possuiu valor 1 , enquanto o interior do Estado possuiu valor 0. Embora o efeito de oceanidade seja mais intenso nas proximidades da faixa litorânea, deve haver uma zona de transição para o interior do Estado. Entende-se que tal efeito deve diminuir fortemente do litoral para os divisores da Serra do Mar, e posteriormente deve haver outra diminuição, mais branda, em direção à Escarpa Devoniana, limite entre o primeiro e o segundo planaltos paranaenses.

Para definição da faixa de transição, foram criados três vetores lineares: o primeiro limita a área de transição à leste, outro à oeste, e um terceiro que segue os divisores da Serra do Mar (Figura 6). Primeiramente, os divisores da Serra do Mar foram delimitados e se aplicou uma área de influência (Buffer) de aproximadamente
$12 \mathrm{~km}$. Essa é uma distância linear aproximada entre os divisores e a área de planície do litoral. A feição linear do Buffer orientada ao interior não foi utilizada, pois o limite ocidental da faixa de transição foi definido a partir dos divisores da Escarpa Devoniana.

O uso da Escarpa Devoniana como limite para a faixa de transição é sustentado pelo efeito de bloqueio que esse relevo possui sobre a Massa Tropical Atlântica. Do primeiro para o segundo planalto paranaense há uma diminuição da pluviosidade média anual (VANHONI, 2015), causada justamente pelo barramento da umidade proveniente do oceano, que não tenha sido realizado na Serra do Mar.

Após a geração das três linhas, foram extraídos pontos em distâncias fixas ao longo delas. $O$ valor 0 foi atribuído aos pontos da margem ocidental da área de influência, o valor 1 foi atribuído aos pontos da margem oriental e o valor 0,5 foi atribuído aos pontos da Serra do Mar. O procedimento de krigeagem foi aplicado sobre essa malha de pontos para geração de uma base matricial com valores entre 0 e 1 . Um gradiente mais pronunciado foi modelado na direção do divisor da Serra do Mar para o litoral ( $50 \%$ da variação em $12 \mathrm{~km}$ ) e um mais fraco para o interior (50\% entre os divisores da Serra do Mar e da Escarpa Devoniana). 


\section{CONDICIONANTES GEOGRÁFICOS DA TEMPERATURA NO AR NO ESTADO DO PARANÁ}

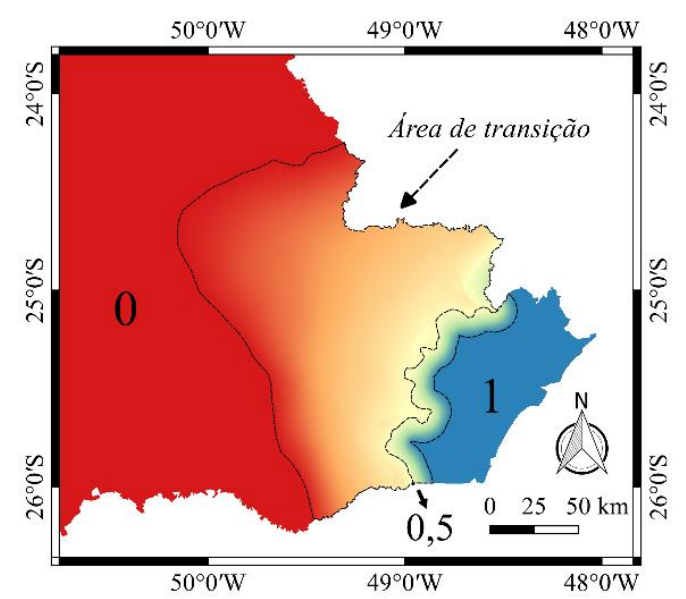

Figura 6 - Detalhe para a área de transição do efeito de oceanidade. Sistema de referência de coordenadas: EPSG 4326 (datum WGS 84 e projeção lat/long).

\subsection{Investigação da contribuição de cada variável}

A análise de regressão descrita no tópico anterior resulta em modelos que podem ser aplicados sobre os valores dos dados em suas unidades originais. No entanto, tais modelos dificultam a interpretação da importância relativa entre os coeficientes angulares de grandezas com diferentes magnitudes (altitude e latitude, por exemplo, observar Tabela 1). Para uma correta comparação entre coeficientes angulares de diferentes variáveis e também para a mesma variável, em meses diferentes, seguiu-se Kutner et al. (2005), que recomendam a normalização das variáveis anteriormente à análise de regressão. Portanto, um novo conjunto de regressões foi elaborado, conforme as variáveis $X$ e $\mathrm{Y}$ normalizadas:

$Y_{i}^{*}=\frac{1}{\sqrt{n-1}}\left(\frac{Y_{i}-r}{S_{Y}}\right)$

$X_{I k}^{s}=\frac{1}{\sqrt{n-1}}\left(\frac{x_{i}-R}{s_{X}}\right)$

Em que:

$\mathrm{Y}^{*}=$ variável dependente normalizada;

$X^{*}=$ variável independente normalizada;

$\bar{Y}=$ média de $Y$;

$\bar{X}=$ média de $X$;

$S_{Y}=$ desvio padrão de $Y$;

$S_{X}=$ desvio padrão de $X$; $\mathrm{n}$ = número de casos.

\subsection{Cálculo da irradiação solar para diferentes} latitudes

Buscou-se compreender o papel das variações intra-anuais da irradiação solar sobre a temperatura do ar em diversas faixas de latitude ao longo do Estado do Paraná. Para isso, foram calculados valores de irradiância sobre o topo da atmosfera para cinco latitudes: $-22,95^{\circ} ;-23,83^{\circ}$; $24,71^{\circ} ;-25,6^{\circ} ;-26,48^{\circ}$. As latitudes mínima e máxima foram definidas, conforme as estações meteorológicas situadas mais ao sul e mais ao norte, respectivamente (Tabela 1). A amplitude foi determinada de forma que as cinco latitudes tivessem o mesmo intervalo.

A energia solar incidente ao longo de um dia sobre o topo da atmosfera foi calculada para o primeiro dia de cada mês, segundo as cinco latitudes definidas. A metodologia para tais cálculos se baseou em Lorenzzetti (2015). Considerando-se a constante solar $E_{s}=1367$ $\mathrm{W} / \mathrm{m}^{2}$, a irradiância para um determinado momento $\left(I_{0}\right)$ é obtida por meio de:

$\mathrm{I}_{0}=\mathrm{E}_{g} \times \mathrm{E}_{0} \cdot(\operatorname{sen} \delta \cdot \operatorname{sen} \phi+\cos \delta \cdot \cos \phi \cdot$ $\cos \omega$ )

Em que:

$\mathrm{E}_{0}=$ fator de ajuste de diferentes distâncias TerraSol no decorrer do ano (adimensional); 


\section{CONDICIONANTES GEOGRÁFICOS DA TEMPERATURA NO AR NO ESTADO DO PARANÁ}

$\delta=\operatorname{declinação~solar~}\left({ }^{\circ}\right)$;

$\Phi=$ latitude $\left({ }^{\circ}\right)$;

$\omega$ = ângulo horário solar $\left({ }^{\circ}\right)$.

Os fatores $E_{0}$ e $\delta$ variam para cada dia do ano, de forma que foram pesquisados em tabelas próprias para o dia primeiro de todos os meses. Para cada um desses dias, a Equação 4 foi repetida 14 vezes, com variações do ângulo horário solar a cada uma hora. Conforme Lorenzzetti (2015), a integração do total de energia recebido ao longo de uma hora pode ser bem aproximada para o resultado do cálculo para o horário central. A transformação da irradiância para energia radiante foi obtida multiplicando-se a primeira por 3,6. Essa multiplicação fornece a energia incidente $(\mathrm{kJ})$ ao longo de uma hora. $\mathrm{O}$ total diário foi obtido a partir do somatório de todas as horas de irradiação solar de cada dia, que variaram entre $10 \mathrm{~h}$ (inverno) e $14 \mathrm{~h}$ (verão).

\section{RESULTADOS E DISCUSSÃO}

\subsection{Reconstituição das séries históricas}

A reconstituição das series históricas envolveu entre uma e quatro estações meteorológicas para estimativa (Tabela 2). Os extremos (1 e 4), no entanto, foram exceções, sendo mais comum o uso de duas ou três estações meteorológicas para a reconstituição.
De maneira geral, os dados do IAPAR foram consistentes com relação às falhas que existem nas séries de temperaturas mínimas, médias e máximas, contendo a mesma porcentagem de dados ausentes. Isso não foi válido apenas para a Estação de Guaraqueçaba (Tabela 2). Já as falhas nas séries de dados do INMET diferem entre si, com relação às três métricas.

Algumas estações não possuem dados ausentes (0\%) e a maioria delas está na faixa < 20\% (Tabela 2). Entretanto, algumas estações como São Miguel do Iguaçu, Cândido de Abreu e Mauá da Serra possuem grandes períodos sem coleta de dados (> 50\%). Ainda assim, tais estações foram mantidas na análise por dois motivos: i) devido às suas especificidades geográficas: São Miguel do Iguaçu é a estação situada mais a oeste do Estado, Cândido de Abreu ocupa um vazio geográfico no centro do Estado e Mauá da Serra é a única estação da porção norte do Estado situada em elevada altitude $(1020 \mathrm{~m})$; ii) devido aos resultados satisfatórios das regressões $\left(0,93<R^{2}<0,99\right)$.

Com relação a tais resultados, observase que a análise de regressão resultou em bons ajustes para as temperaturas mínimas, médias e máximas, embora haja uma tendência de terem sido um pouco melhores para as médias (Tabela 2).

Tabela 2 - Reconstituição de séries históricas: dados ausentes e descrição dos resultados das análises de regressão. $k$ = número de estações utilizadas para o preenchimento. $R^{2}=R^{2}$ ajustado. $O$ valor $p$ para o teste $\mathrm{F}$ de razão entre variâncias para todas as regressões foi $<2,2 \cdot 10^{-16}$.

\begin{tabular}{|c|c|c|c|c|c|c|c|}
\hline \multirow{2}{*}{ Estação } & \multirow{2}{*}{$k$} & \multirow{2}{*}{$\mathbf{R}^{\mathbf{2}} \mathbf{M i n}$} & \multirow{2}{*}{$\mathbf{R}^{2}$ Med } & \multirow{2}{*}{$\mathbf{R}^{2} \operatorname{Max}$} & \multicolumn{3}{|c|}{ Dados ausentes (\%) } \\
\hline & & & & & Min & Med & Max \\
\hline Campo Mourão & 2 & 0,93 & 0,96 & 0,96 & 2,5 & 10,4 & 10,4 \\
\hline Castro & 2 & 0,97 & 0,98 & 0,97 & 16,1 & 23,8 & 21 \\
\hline Curitiba & 2 & 0,96 & 0,96 & 0,98 & 3,2 & 3,4 & 3,4 \\
\hline Ivaí & 2 & 0,96 & 0,98 & 0,95 & 18 & 21,7 & 21,2 \\
\hline Maringá & 3 & 0,97 & 0,98 & 0,98 & 12,5 & 13 & 13 \\
\hline Paranaguá & 1 & 0,98 & 0,99 & 0,97 & 6,4 & 20 & 20 \\
\hline Bela V. Paraíso & \multicolumn{4}{|c|}{-} & \multicolumn{3}{|c|}{0} \\
\hline Joaquim Távora & 3 & 0,97 & 0,98 & 0,96 & \multicolumn{3}{|c|}{0,2} \\
\hline Cambará & 2 & 0,98 & 0,99 & 0,98 & \multicolumn{3}{|c|}{11,3} \\
\hline Bandeirantes & \multicolumn{4}{|c|}{-} & \multicolumn{3}{|c|}{0} \\
\hline Londrina & \multicolumn{4}{|c|}{-} & \multicolumn{3}{|c|}{0} \\
\hline
\end{tabular}


MONTANHER, O. C., MINAKI, C.

\section{CONDICIONANTES GEOGRÁFICOS DA TEMPERATURA NO AR NO ESTADO DO PARANÁ}

\begin{tabular}{|c|c|c|c|c|c|c|c|}
\hline Apucarana & 3 & 0,98 & 0,99 & 0,98 & \multicolumn{3}{|c|}{32,7} \\
\hline Ibiporã & 3 & 0,99 & 0,99 & 0,98 & \multicolumn{3}{|c|}{1,3} \\
\hline Mauá da Serra & 2 & 0,98 & 0,99 & 0,98 & \multicolumn{3}{|c|}{66} \\
\hline Paranavaí & \multicolumn{4}{|c|}{-} & \multicolumn{3}{|c|}{0} \\
\hline Cianorte & 4 & 0,99 & 0,99 & 0,99 & \multicolumn{3}{|c|}{34,8} \\
\hline Umuarama & \multicolumn{4}{|c|}{-} & \multicolumn{3}{|c|}{0} \\
\hline Cerro Azul & 3 & 0,97 & 0,98 & 0,97 & \multicolumn{3}{|c|}{45} \\
\hline Telêmaco Borba & \multicolumn{4}{|c|}{-} & \multicolumn{3}{|c|}{0} \\
\hline Candido de Abreu & 3 & 0,99 & 0,99 & 0,99 & \multicolumn{3}{|c|}{72,4} \\
\hline Nova Cantú & 2 & 0,98 & 0,99 & 0,96 & \multicolumn{3}{|c|}{5,1} \\
\hline Palotina & 3 & 0,95 & 0,97 & 0,97 & \multicolumn{3}{|c|}{10,2} \\
\hline Cascavel & 3 & 0,98 & 0,99 & 0,97 & & 43,1 & \\
\hline Morretes & \multicolumn{4}{|c|}{-} & \multicolumn{3}{|c|}{0} \\
\hline Guaraqueçaba & 2 & 0,99 & 0,99 & 0,99 & 3,2 & 4,9 & 3 \\
\hline Antonina & 2 & 0,98 & 0,99 & 0,99 & \multicolumn{3}{|c|}{43,1} \\
\hline Lapa & 2 & 0,99 & 0,99 & 0,99 & \multicolumn{3}{|c|}{30,4} \\
\hline Ponta Grossa & 2 & 0,99 & 0,99 & 0,98 & \multicolumn{3}{|c|}{34,2} \\
\hline Fernandes Pinheiro & \multicolumn{4}{|c|}{-} & \multicolumn{3}{|c|}{0} \\
\hline Guarapuava & \multicolumn{4}{|c|}{-} & \multicolumn{3}{|c|}{0} \\
\hline Laranjeiras do Sul & 3 & 0,98 & 0,99 & 0,99 & \multicolumn{3}{|c|}{18,3} \\
\hline Planalto & \multicolumn{4}{|c|}{-} & \multicolumn{3}{|c|}{0} \\
\hline Quedas do Iguaçu & 3 & 0,98 & 0,99 & 0,99 & \multicolumn{3}{|c|}{41,6} \\
\hline São Miguel do Iguaçu & 3 & 0,99 & 0,99 & 0,99 & \multicolumn{3}{|c|}{61,1} \\
\hline Palmas & 2 & 0,98 & 0,99 & 0,98 & \multicolumn{3}{|c|}{5,7} \\
\hline Clevelândia & 2 & 0,98 & 0,99 & 0,98 & \multicolumn{3}{|c|}{7,2} \\
\hline Francisco Beltrão & \multicolumn{4}{|c|}{-} & \multicolumn{3}{|c|}{0} \\
\hline
\end{tabular}

\subsection{Modelos para estimativa da temperatura do}

ar

Os modelos para estimativa da temperatura do ar estão descritos nas Tabelas 3, 4 e 5. Os valores críticos para o teste de significância dos coeficientes das regressões, com base na estatística t, para 32, 33 e 34 graus de liberdade são, respectivamente, 2,0369, 2,0345 e 2,0322. De modo geral, os modelos para explicação da temperatura média do ar tiveram resultados satisfatórios (Tabela 3: 0,88 $<\mathrm{R}^{2}<$ $0,97)$. A altitude, a latitude e a longitude foram variáveis importantes em todos os meses e também para a média anual (Tabela 3). Nenhum desses coeficientes foi não significativo, ou excluído do modelo segundo o AIC. Já a variável região não foi selecionada para determinação da média térmica anual e dos meses de abril, agosto e setembro.
O sinal negativo dos coeficientes da altitude em todos os casos denota a reconhecida relação inversa entre a altitude e a temperatura do ar. Os valores positivos dos coeficientes da latitude mostram que, quanto mais para o sul, menor a temperatura do ar, relação também reconhecida em climatologia. Isso porque os valores de latitude estão entre $0^{\circ}$ e $-90^{\circ}$ (Tabela 1). O sinal negativo dos coeficientes da longitude mostra que, quanto mais para oeste, maior a temperatura média do ar, pois os valores de longitude estão entre $0^{\circ} \mathrm{e}-180^{\circ}$.

Ao contrário das outras três variáveis, a região apresentou uma dinâmica mais complexa no decorrer do ano. Nos seis meses mais quentes do ano, a região do litoral teve entre $0,48^{\circ} \mathrm{C}$ e $1,23^{\circ} \mathrm{C}$ a menos em relação ao interior. Nos meses de inverno a relação foi inversa, e a região do litoral apresentou temperaturas entre $1,04^{\circ} \mathrm{C}$ 


\section{CONDICIONANTES GEOGRÁFICOS DA TEMPERATURA NO AR NO ESTADO DO PARANÁ}

e $1,38^{\circ} \mathrm{C}$ a mais do que o interior. Essas diferenças podem ser interpretadas com base no efeito de oceanidade, em que a água, devido à sua capacidade térmica, ameniza as maiores temperaturas e mantém a temperatura um pouco mais elevada nos períodos mais frios. Um fato interessante é que essa variável, que tenta reproduzir o efeito de oceanidade, não foi importante para as estações de transição (outono e primavera).

Tabela 3 - Modelos para estimativa da temperatura média do ar: médias mensais. Coeficientes não significativos para $\alpha=0,05$ estão em negrito.

\begin{tabular}{|c|c|c|c|c|c|c|}
\hline Período & Intercepto & Altitude & Latitude & Longitude & Região - lit & $\mathbf{R}^{\mathbf{2}}$ \\
\hline Janeiro & 23,43 & $-0,005748$ & 0,3411 & $-0,2333$ & $-1,14$ & 0,969 \\
\hline Fevereiro & 30,09 & $-0,005556$ & 0,4335 & $-0,1437$ & $-0,84$ & 0,972 \\
\hline Março & 28,42 & $-0,005334$ & 0,6477 & $-0,2616$ & $-\mathbf{0 , 4 8}$ & 0,970 \\
\hline Abril & 34,77 & $-0,004953$ & 0,9004 & $-0,2125$ & & 0,957 \\
\hline Maio & 34,33 & $-0,004079$ & 1,0323 & $-0,2076$ & $\mathbf{1 , 1 7}$ & 0,929 \\
\hline Junho & 30,08 & $-0,003345$ & 1,1123 & $-0,2936$ & 1,38 & 0,900 \\
\hline Julho & 30,71 & $-0,003276$ & 1,1977 & $-0,3192$ & $\mathbf{1 , 0 4}$ & 0,888 \\
\hline Agosto & 29,57 & $-0,003633$ & 1,2538 & $-0,4056$ & & 0,886 \\
\hline Setembro & 29,44 & $-0,003906$ & 1,2835 & $-0,4491$ & & 0,944 \\
\hline Outubro & 27,23 & $-0,004785$ & 1,0709 & $-0,4450$ & $-0,95$ & 0,965 \\
\hline Novembro & 26,53 & $-0,005269$ & 0,7926 & $-0,3555$ & $-1,17$ & 0,967 \\
\hline Dezembro & 24,11 & $-0,005642$ & 0,4884 & $-0,2820$ & $-1,23$ & 0,969 \\
\hline Média anual & 28,59 & $-0,004494$ & 0,9005 & $-0,3182$ & & 0,952 \\
\hline
\end{tabular}

Os modelos para explicação das temperaturas mínimas não tiveram resultados tão bons quanto os modelos de temperaturas médias, e também tiveram uma maior variabilidade intra-anual (Tabela 4: 0,72 $<\mathrm{R}^{2}<$ 0,93). Assim como os resultados das temperaturas médias, a altitude, a latitude e a longitude foram variáveis importantes em todos os meses e também para a temperatura média mínima anual (Tabela 4). A dinâmica das relações dessas três variáveis foi a mesma em comparação aos modelos de temperaturas médias. Por outro lado, a variável região apresentou uma dinâmica diferente, possuindo apenas valores positivos, principalmente para os meses mais frios do ano. Isso mostra que as mínimas são maiores no litoral nesse período, em comparação a uma área no interior em situação geográfica semelhante.

Tabela 4 - Modelos para estimativa da temperatura média do ar: mínimas mensais. Coeficientes não significativos para $\alpha=0,05$ estão em negrito.

\begin{tabular}{|c|c|c|c|c|c|c|}
\hline Período & Intercepto & Altitude & Latitude & Longitude & Região - lit & $\mathbf{R}^{\mathbf{2}}$ \\
\hline Janeiro & 24,79 & $-0,004844$ & 0,5074 & $-0,1917$ & & 0,939 \\
\hline Fevereiro & 29,10 & $-0,004817$ & 0,4775 & $-0,0940$ & & 0,931 \\
\hline Março & 27,59 & $-0,004384$ & 0,6708 & $-0,1925$ & $\mathbf{0 , 8 5}$ & 0,909 \\
\hline Abril & 30,04 & $-0,003873$ & 0,8685 & $-\mathbf{0 , 1 9 0 6}$ & 1,61 & 0,871 \\
\hline Maio & 26,52 & $-0,003216$ & 1,0408 & $-0,2702$ & 2,65 & 0,814 \\
\hline Junho & 18,70 & $-0,002520$ & 1,1047 & $-0,4177$ & 2,99 & 0,759 \\
\hline Julho & 18,74 & $-0,002255$ & 1,1745 & $-0,4388$ & 3,06 & 0,732 \\
\hline Agosto & $\mathbf{1 5 , 4 5}$ & $-0,002211$ & 1,2588 & $-0,5638$ & 3,04 & 0,720 \\
\hline Setembro & $\mathbf{2 5 , 0 4}$ & $-0,003290$ & 1,1278 & $-0,3575$ & $\mathbf{1 , 6 1}$ & 0,855 \\
\hline Outubro & $\mathbf{2 4 , 6 3}$ & $-0,004544$ & 0,8593 & $-0,2980$ & & 0,918 \\
\hline
\end{tabular}




\section{CONDICIONANTES GEOGRÁFICOS DA TEMPERATURA NO AR NO ESTADO DO PARANÁ}

\begin{tabular}{|c|c|c|c|c|c|c|} 
Novembro & 26,09 & $-0,004691$ & 0,7592 & $-0,2462$ & & 0,932 \\
\hline Dezembro & 24,57 & $-0,004771$ & 0,6128 & $-0,2329$ & & 0,940 \\
\hline Média anual & 23,89 & $-0,003683$ & 0,8878 & $-0,3049$ & $\mathbf{1 , 4 6}$ & 0,867 \\
\hline
\end{tabular}

Os modelos para explicação das temperaturas máximas apresentaram resultados consistentes ao longo do ano (Tabela 5: 0,92 $<\mathrm{R}^{2}$ $<0,94)$. A altitude foi a única variável selecionada em todos os meses do ano, enquanto a latitude não foi selecionada apenas para o mês de janeiro. Por outro lado, a longitude não foi selecionada em seis meses do ano e foi não significativa em outros dois meses (Tabela 5). Aparentemente, a longitude possui relação com as temperaturas máximas apenas em estações de transição (outono e primavera).

A variável região foi importante em todos os meses do ano para explicar as máximas. Ao contrário de valores positivos (por exemplo, segundo as mínimas), nesse caso, a região do litoral possuiu valores negativos. Tais valores são maiores durante o verão, período em que as máximas normalmente se elevam.

Tabela 5 - Modelos para estimativa da temperatura média do ar: máximas mensais. Coeficientes não significativos para $\alpha=0,05$ estão em negrito.

\begin{tabular}{|c|c|c|c|c|c|c|}
\hline Período & Intercepto & Altitude & Latitude & Longitude & Região - lit & $\mathbf{R}^{\mathbf{2}}$ \\
\hline Janeiro & 34,29 & $-0,007495$ & & & $-3,75$ & 0,942 \\
\hline Fevereiro & 37,77 & $-0,007280$ & 0,1475 & & $-3,58$ & 0,936 \\
\hline Março & 34,43 & $-0,007046$ & 0,3394 & $-0,1432$ & $-3,82$ & 0,935 \\
\hline Abril & 46,70 & $-0,006765$ & 0,6336 & & $-3,75$ & 0,922 \\
\hline Maio & 46,43 & $-0,005617$ & 0,7959 & & $-1,72$ & 0,948 \\
\hline Junho & 47,74 & $-0,004898$ & 0,9193 & & $-1,40$ & 0,943 \\
\hline Julho & 50,76 & $-0,005248$ & 1,0229 & & $-2,01$ & 0,949 \\
\hline Agosto & 48,29 & $-0,005356$ & 1,1125 & $-\mathbf{0 , 1 3 5 5}$ & $-3,30$ & 0,947 \\
\hline Setembro & 42,77 & $-0,005739$ & 1,1089 & $-0,2591$ & $-3,19$ & 0,938 \\
\hline Outubro & 40,55 & $-0,006200$ & 0,9579 & $-0,2752$ & $-3,59$ & 0,941 \\
\hline Novembro & 37,50 & $-0,006765$ & 0,5286 & $-0,1592$ & $-3,77$ & 0,933 \\
\hline Dezembro & 32,70 & $-0,007188$ & $\mathbf{0 , 1 5 3 6}$ & $-\mathbf{0 , 0 9 3 3}$ & $-3,59$ & 0,940 \\
\hline Média anual & 41,94 & $-0,006436$ & 0,6198 & $-\mathbf{0 , 0 7 4 3}$ & $-3,28$ & 0,959 \\
\hline
\end{tabular}

\subsection{Espacialização da temperatura do ar}

Os modelos apresentados nas Tabelas 3, 4 e 5 permitiram a espacialização da temperatura do ar (Figura 7) a partir da álgebra de mapas em ambiente SIG, feita sobre as bases matriciais apresentadas na Figura 5. A apresentação de todos esses mapeamentos neste artigo seria inviável devido à sua extensão, pois consistem em 39 variáveis (três valores anuais e 36 mensais). Entretanto, um exemplo é apresentado, das temperaturas médias anuais ao longo do Estado. Todos os 39 mapas serão disponibilizados pelo primeiro autor em sua página pessoal do ResearchGate.

\subsection{Análise da contribuição das variáveis}

Embora os modelos apresentados nas Tabelas 3, 4 e 5 sejam os indicados para estimativa da temperatura do ar, os mesmos não proporcionam uma avaliação da continuidade temporal da importância das quatro variáveis ao longo do ano. Este tópico apresenta os resultados dos modelos padronizados, em que os coeficientes são apresentados em valores reais e absolutos (Figuras 8, 9 e 10), sendo que a transformação para valores absolutos permitiu uma comparação ainda mais direta.

Uma avaliação rápida das Figuras 8, 9 e 10 mostrou que a altitude e a latitude foram as variáveis mais importantes para explicação das 


\section{CONDICIONANTES GEOGRÁFICOS DA TEMPERATURA NO AR NO ESTADO DO PARANÁ}

três métricas da temperatura do ar. A altitude tem um efeito que se sobressai nos meses mais quentes do ano, enquanto a latitude prepondera nos meses mais frios. É interessante notar que essas duas variáveis possuem uma dinâmica complementar no decorrer do ano, pois quando uma é mais forte, a outra é mais fraca.
A latitude chega a ser mais importante do que a altitude nos meses de inverno para as temperaturas médias e principalmente para as mínimas. Já para as temperaturas máximas, a altitude detém forte efeito em todo o ano.

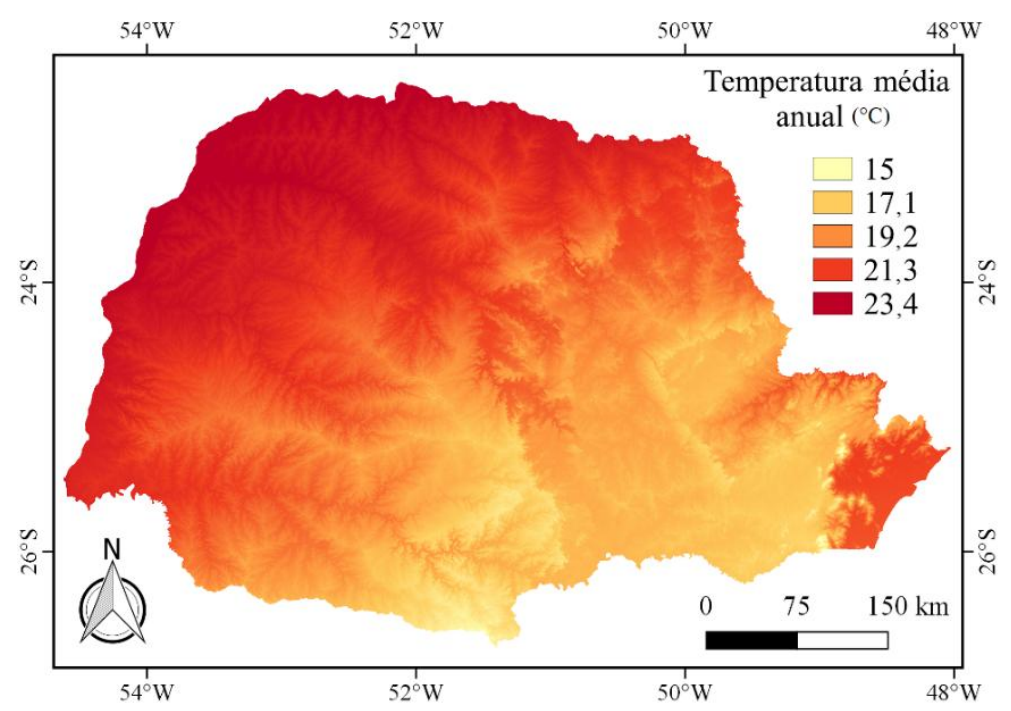

Figura 7 - Exemplo de espacialização da temperatura do ar para o Estado do Paraná. Sistema de referência de coordenadas: EPSG 4326 (datum WGS 84 e projeção lat/long).

Em geral, as variáveis longitude e região são menos importantes para os modelos, principalmente para as médias mensais. Com relação às mínimas, a longitude chega a ter um efeito maior do que a altitude nos meses de inverno. Já para as máximas, a variável região se destaca, com influência maior do que a soma dos efeitos de latitude e longitude, para os meses de verão. A preponderância da oceanidade sobre as máximas foi mencionada nos resultados dos modelos convencionais.
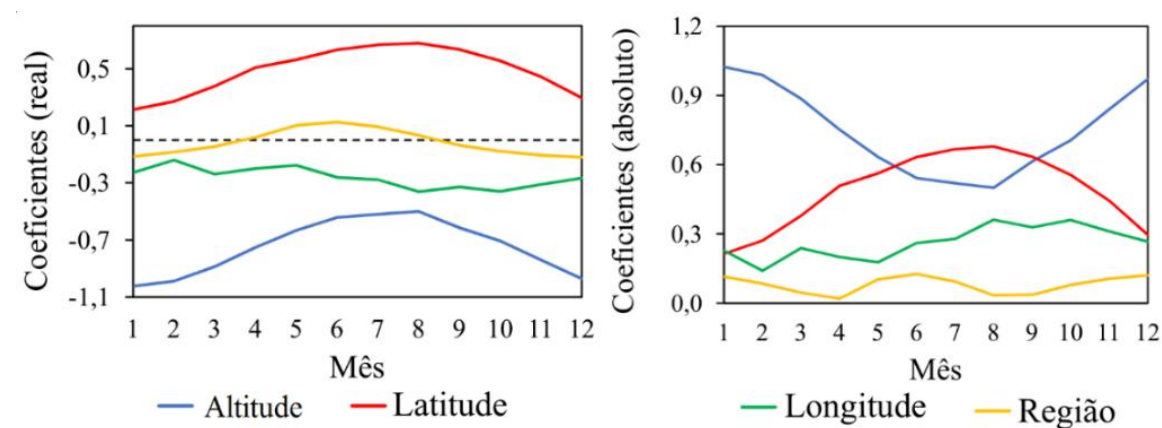

Figura 8 - Coeficientes da regressão padronizada: médias (médias mensais).

De modo geral, observa-se que, embora as outras variáveis também sejam importantes em períodos específicos, a altitude e a latitude são os fatores que mais controlam a temperatura do ar. Além disso, pela variação apresentada ficou evidenciado que a altitude é mais 


\section{CONDICIONANTES GEOGRÁFICOS DA TEMPERATURA NO AR NO ESTADO DO PARANÁ}

importante no verão, enquanto a latitude é mais importante no inverno. Durante o verão, não há grande variação de irradiação solar ao longo do Estado (principalmente entre outubro e março). No entanto, nos meses de inverno, a diferença de incidência de radiação entre as estações que estão mais a norte e mais a sul aproxima-se de $9 \%$ (Figura 11). Como há uma maior variação da energia solar ao longo do Estado durante o inverno, isso deve explicar, em parte, porque a latitude é mais importante nesta época do ano.
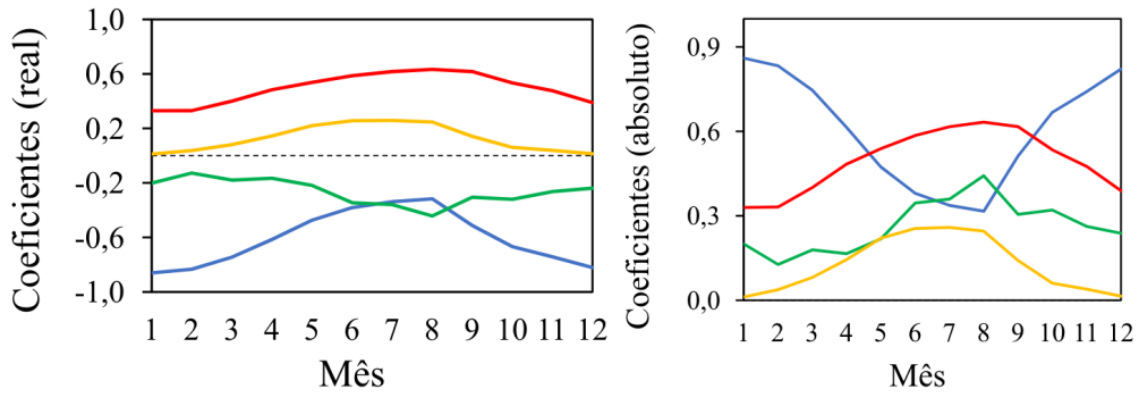

- Altitude - Latitude

— Longitude - Região

Figura 9 - Coeficientes da regressão padronizada: mínimas (médias mensais).
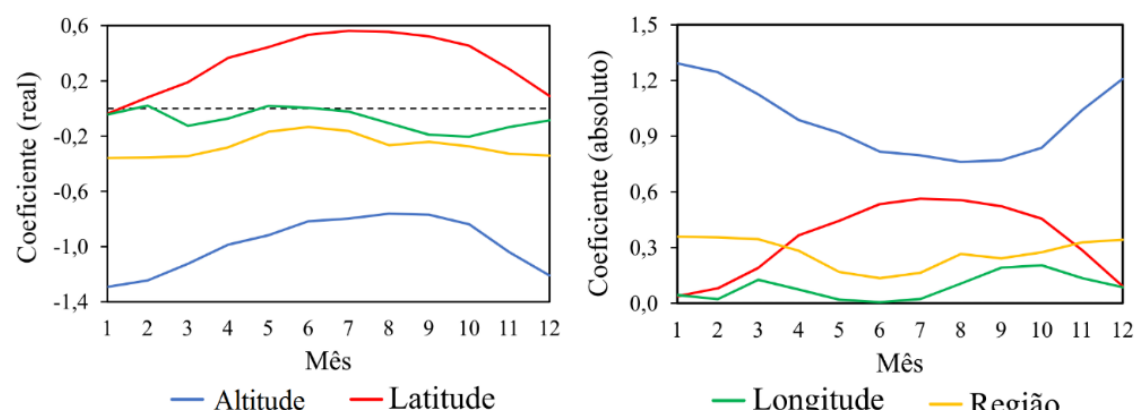

Figura 10 - Coeficientes da regressão padronizada: máximas (médias mensais).

Considerando que os valores apresentados na Figura 11 são para o topo da atmosfera, a diferença percentual da energia que atinge a superfície deve ser ainda maior do que $9 \%$, pois a atenuação da radiação solar ao longo da atmosfera não foi levada em conta. Além da radiação solar, outro fator que deve explicar o porquê de a latitude ser uma variável mais importante durante o inverno é a entrada de massas de ar polar, principalmente pelo extremo sul da América do Sul, e que perdem suas características mais extremas com o avanço sobre o interior do continente. 


\section{CONDICIONANTES GEOGRÁFICOS DA TEMPERATURA NO AR NO ESTADO DO PARANÁ}

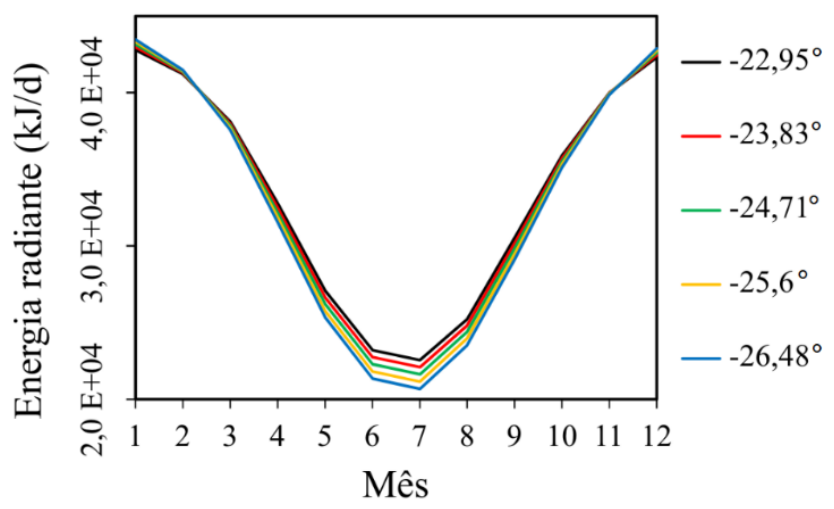

Figura 11 - Variação anual do total diário de radiação solar incidente sobre o topo da atmosfera para diversas latitudes ao longo do Estado do Paraná.

\section{CONCLUSÃO}

As seguintes conclusões foram obtidas:

i) As equações dos modelos convencionais de regressão permitem a espacialização dos valores mensais e anuais das temperaturas mínimas, médias e máximas;

ii) A altitude e a latitude tiveram relações inversamente proporcionais, enquanto a longitude teve uma relação proporcional com a temperatura. A variável região, proposta como uma tentativa de simular o forte efeito de oceanidade que ocorre no litoral do Estado, apresentou-se de forma mais complexa. Sua dinâmica no decorrer do ano e entre as métricas mínimas, médias e máximas, foi de amenizar os valores extremos para a região do litoral, conforme o que se espera de uma área influenciada por extensa superfície hídrica;

iii) Todas as variáveis analisadas possuíram forte variação intra-anual, ressaltando-se a dinâmica oposta entre a altitude e a latitude;

iv) Com relação à diferença de importância entre as variáveis, conforme a métrica, se identificou principalmente que a variável região não foi homogênea entre os valores mínimos, médios e máximos;

v) Conclui-se que as variáveis moduladoras da temperatura do ar possuem variação significativa entre as métricas e ao longo do ano no Estado do Paraná.

\section{AGRADECIMENTOS}

Agradecemos às políticas de distribuição de dados do INMET e do IAPAR, bem como aos desenvolvedores dos softwares QGIS e R, pelo fornecimento gratuito desses produtos. Agradecemos também ao trabalho feito pelos revisores, principalmente pelas sugestões de bibliografia e pela sugestão no tratamento do efeito de oceanidade.

\section{REFERÊNCIAS}

BARBARISI, B.F.; PILAU, F.G.; MARIN, F.R.; ASSAD, E.D.; PINTO, H.S. Estimativa da temperatura do ar para os Estados de Mato Grosso do Sul, Mato Grosso, Goiás e Tocantins a partir do uso de imagens de radar. In: CONGRESSO BRASILEIRO DE METEOROLOGIA, 14, 2006, Florianópolis, 2006.

BARDIN, L.; PEDRO JÚNIOR, M.J.; MORAES, J.F.L. Estimativa das temperaturas máximas e mínimas do ar para a região do Circuito das Frutas, SP. Revista Brasileira de Engenharia Agrícola e Ambiental, Campina Grande, v. 14, n. 6, p. 618624, 2010.

BARRY, R.G.; CHORLEY, R.J. Atmosfera, tempo e clima. 9. ed. Porto Alegre: Ed. Bookman, 2013.

BRASIL. Ministério da Agricultura, Pecuária e Abastecimento. Instituto Nacional de Meteorologia. Banco de Dados Meteorológicos para Ensino e Pesquisa do INMET. Disponível em: $<$ http://www.inmet.gov.br/projetos/rede/pesqui sa/>. Acesso em: 05 maio 2017. 


\section{CONDICIONANTES GEOGRÁFICOS DA TEMPERATURA NO AR NO ESTADO DO PARANÁ}

CARGNELUTTI FILHO, A.; MALUF, J.R.T.; MATZENAUER, R. Coordenadas geográficas na estimativa das temperaturas máxima e média decendiais do ar no Estado do Rio Grande do Sul. Ciência Rural, Santa Maria, v. 38, n. 9, p. 24482456, 2008.

CARGNELUTTI FILHO, A.; MALUF, J.R.T.; MATZENAUER, R.; STOLZ, A.P. Altitude e coordenadas geográficas na estimativa da temperatura mínima média decendial do ar no Estado do Rio Grande do Sul. Pesquisa Agropecuária Brasileira, Brasília, v. 41, n. 6, p. 893-901, jun. 2006.

IAPAR. Redes de estações - Instituto Agronômico do Paraná - IAPAR. Disponível em: <http://www.iapar.br/pagina-890.html>. Acesso em: 30 abr. 2017.

KUTNER, M.H., NACHTSHEIM, C.J., NETER, J., LI, W. Applied Linear Statistical Models. 5. ed. Boston: McGraw-Hill, 2005.

LORENZZETTI, J. A. Princípios físicos de Sensoriamento Remoto. São Paulo: Blucher. 2015.

MELLO, Y.R.; KOHLS, W.; OLIVEIRA, T.M.N. Uso de diferentes métodos para o preenchimento de falhas em estações pluviométricas. Boletim de Geografia, Maringá, v. 35, n. 1, p. 112-121, 2017.

MENDONÇA. F.; DANNI-OLIVEIRA, I.M. Climatologia: noções básicas e climas do Brasil. São Paulo: Oficina de Textos, 2007.

OLIVEIRA NETO, S.N.; REIS, R.G.; REIS, M.G.F.; LEITE, H.G. Estimativa de temperaturas para o território brasileiro localizado entre 16 e 24 o latitude Sul e 48ㅇ e 60ㅇ longitude Oeste. In: CONGRESSO BRASILEIRO DE METEOROLOGIA, 11, 2000, Rio de Janeiro-RJ, p. 926-931.

PAULA, E. V. Dengue: uma análise climatogeográfica de sua manifestação no estado do Paraná (1993-2003). 164 f. Dissertação de mestrado. UFPR - Universidade Federal do Paraná. Curitiba. 2005.

QGIS DEVELOPMENT TEAM. QGIS Geographic Information System. Open Source Geospatial Foundation. 2009. Disponível em: <http://qgis.osgeo.org $\geq$. Acesso em: 30 abr. 2017.

R CORE TEAM. R: A language and environment for statistical computing. $\mathrm{R}$ Foundation for Statistical Computing, Vienna, Austria. 2017. Disponível em: <https://www.R-project.org/>. Acesso em: 02 mar. 2017.

RICCE, W.S.; CARVALHO, S.L.C.; CARAMORI, P.H.; AULER, P.A.M.; ROBERTO, S.R. Zoneamento agroclimático da cultura da videira no Estado do Paraná. Semina: Ciências Agrárias, Londrina, v. 35 , n. 4, suplemento, p. 2327-2336, 2014a.

RICCE, W.S.; CARVALHO, S.L.C.; CARAMORI, P.H.; AULER, P.A.M.; ROBERTO, Sergio Ruffer. Zoneamento agroclimático da cultura do abacaxizeiro no Estado do Paraná. Semina: Ciências Agrárias, Londrina, v. 35, n. 4, suplemento, p. 2337-2346, 2014b.

USGS. Shuttle Radar Topography Mission (SRTM) - The Long Term Archive. Disponível em: <https://Ita.cr.usgs.gov/SRTM>. Acesso em: 01 ago. 2017.

VALERIANO, M.M.; PICINI, A.G. Uso de Sistema de Informação Geográfica para a geração de mapas de médias mensais de temperatura do Estado de São Paulo. Revista Brasileira de Agrometeorologia, v. 8, n. 2, p. 255-262, 2000.

VALERIANO, M.M.; PICINI, A.G. Geoprocessamento de informações agroclimatológicas. MCTI - INPE-10128RPQ/751. São José dos Campos, 2003.

VANHONI, F. A dinâmica pluvial do clima subtropical: variabilidade e tendência no sul do 
MONTANHER, O. C., MINAKI, C.

\section{CONDICIONANTES GEOGRÁFICOS DA TEMPERATURA NO AR NO ESTADO DO PARANÁ}

Brasil. 166 f. Tese de doutorado. UFPR Universidade Federal do Paraná. Curitiba. 2015.

VANHONI, F. MENDONÇA, F. O Clima do litoral do Estado do Paraná. Revista Brasileira de Climatologia, v. 3, v. 3\&4, 2008.

VAREJÃO-SILVA, M.A. Meteorologia e Climatologia. Versão digital 2. Recife, mar. 2006.

VENTURA, T.M.; SANTANA, L.L.R.; MARTINS, C.A.; FIGUEIREDO, J.M. Análise da aplicabilidade de métodos estatísticos para preenchimento de falhas em dados meteorológicos. Revista Brasileira de Climatologia. v. 19, p. 168-177, 2016.

ZAMBRANO-BIGIARINI, M. hydroTSM: Time series management, analysis and interpolation for hydrological modelling. $\mathrm{R}$ package version 0.4-21.

2014. 